\title{
Proteasome inhibitors and knockdown of SMG1 cause accumulation of Upf1 and Upf 2 in human cells
}

\author{
XIA ZHAO ${ }^{1,2}$, ATSUSHI NOGAWA ${ }^{3}$, TSUKASA MATSUNAGA ${ }^{3}$, TSUTOMU TAKEGAMI ${ }^{2}$, \\ HIDEAKI NAKAGAWA $^{2}$ and YASUHITO ISHIGAKI ${ }^{2}$ \\ ${ }^{1}$ Institute of Pathology, Tongji Hospital, Tongji Medical College, Huazhong University of Science and Technology, \\ Wuhan 430030, P.R. China; ${ }^{2}$ Medical Research Institute, Kanazawa Medical University, Kahoku 920-0293; \\ ${ }^{3}$ Laboratory of Human Molecular Genetics, School of Pharmaceutical Sciences, \\ Kanazawa University, Kakuma, Kanazawa 920-1192, Japan
}

Received July 27, 2013; Accepted September 23, 2013

DOI: $10.3892 /$ ijo.2013.2149

\begin{abstract}
The ubiquitin-proteasome system (UPS) is one of the most promising anticancer drug targets of the century. However, the involved molecular mechanisms are still unclear. The nonsense-mediated mRNA decay (NMD) pathway is a highly conserved pathway which degrades nonsense mutation-containing mRNA selectively and efficiently. In this pathway, the SMG1-Upf1-eRF (SURF) complex binds to Upf2 on the exon junction complex and finally causes degradation of nonsense-containing mRNA. To reveal the relationship between the UPS and NMD pathways, we analyzed the effects of proteasome inhibitors on Upf1 and Upf2. The data showed that treatment with proteasome inhibitors caused the accumulation of the Upf 1 and Upf 2 proteins in A549 cells. In addition, we found that knockdown of SMG1 also caused the upregulation of Upf1 and Upf 2 proteins, which was confirmed by different target sequences of siRNA. SMG1 and UPS appear to participate in different pathways of the degradation of Upf1 and Upf2, since simultaneous treatment with both of them caused additive effects. This study demonstrated the quantitative regulation of Upf1 and Upf2 proteins by UPS and SMG1.
\end{abstract}

\section{Introduction}

Ubiquitin-proteasome system (UPS) is a well-known specific protein degradation pathway. It plays major roles in multiple

Correspondence to: Dr Yasuhito Ishigaki, Medical Research Institute, Kanazawa Medical University, Daigaku 1-1, Uchinada-machi, Kahoku-gun 920-0293, Japan

E-mail: ishigaki@kanazawa-med.ac.jp

Abbreviations: CHX, cycloheximide; LAC, lactacystin; MG, MG132; NMD, nonsense mediated mRNA decay; SURF, SMG1-Upf1-eRF; UPS, ubiquitin-proteasome system; WORT, wortmannin

Key words: nonsense mediated mRNA decay, SMG1, ubiquitin, proteasome, Upf1, Upf2 biological processes such as proteins turnover, cell cycle control, antigen processing, signal transduction, protein quality control, cell differentiation and apoptosis $(1,2)$. It has been found that tumor cells are more sensitive to proteasome inhibitors than normal cells. Today, the proteasome is one of the most promising targets of anticancer drug, but the involved molecular mechanisms are still unclear.

Gene expression is regulated by various mechanisms in which RNA decay pathway is one of the most important regulators. Nonsense mediated mRNA decay (NMD) is a highly conserved pathway which degrades the nonsense mutation (also called premature termination codon) containing mRNA selectively $(3,4)$. In addition to nonsense-mutation in genome, transcription error, alternative splicing and RNA editing can also bear targets of NMD (5). However, little was known about the relationship between NMD pathway and UPS.

During the whole NMD pathway, Upf1, Upf2 and Upf3 proteins are essential for NMD (6). SMG1 is a member of PI3KK family and phosphorylates Upf1 (7). SMG1 and Upf1 form a complex with translation termination factors eRF1 and eRF3 (SURF) and this complex formation is essential for $\operatorname{NMD}(8,9)$. Upf 2 is recruited to mRNA via binding to $N$ terminus of Upf $3 b$ that is a component of exon-exon junction complex on mRNA molecule $(10,11)$. Then, SURF interacts with both Upf2 and stalled ribosome on nonsense codon and induces the rapid degradation of aberrant mRNA following decapping.

In the present study, we analyzed the effect of UPS on NMD components which keep the genetic integrity. The results may help us understand the mechanisms underlining the anticancer effect of UPS inhibitors.

\section{Materials and methods}

Cell culture and siRNA transfection. A549 cells were cultured with Dulbecco's modified Eagle's medium (Sigma-Aldrich, St. Louis, MO, USA) supplemented with FBS (Sigma-Aldrich) and antibiotics (Penicillin, Wako Pure Chemical Industries Ltd., Osaka, Japan). Cells $\left(0.8-2.0 \times 10^{5}\right)$ were inoculated into 12-well plate one day before transfection. RNAiFect transfection kit (Qiagen GmbH, Hilden, Germany) was used following 
the manufacturer's protocol. The following were target sequences of siRNA: control luciferase, CGUACGCGGAAU ACUUCGA; SMG1-1 (5032), AAGAUGAAUGGUGGA GAGUUA. SMG1-2 (2999), GCAGAAAGGUGGUUGACAA; control luciferase was from B-Bridge Inc. (Tokyo, Japan). SMG1-1 (5032) was purchased from Dharmacon (Thermo Fisher Scientific Inc., Waltham, MA, USA) and SMG1-2 (2999) was purchased from Nippon EGT Co., Ltd. (Tokyo, Japan).

Chemical reagents. Cells were treated with $100 \mu \mathrm{g} / \mathrm{ml}$ cycloheximide (Sigma-Aldrich), 20 to $30 \mu \mathrm{M}$ MG132 (Calbiochem, Merck KGaA, Darmstadt, Germany), $20 \mu \mathrm{M}$ lactacystin (Calbiochem) or $10 \mu \mathrm{M}$ wortmannin (Calbiochem) for $12 \mathrm{~h}$, and each was dissolved in DMSO as stock solution.

Western blot analysis. Cell lysates were prepared with lysis buffer (50 mM Tris-HCl, $150 \mathrm{mM} \mathrm{NaCl,} \mathrm{1.0 \%} \mathrm{Nonidet} \mathrm{P-40)}$ supplemented with protease inhibitor cocktail (Complete mini, EDTA-free, F. Hoffmann-La Roche Ltd., Basel, Switzerland) on ice. NE-PER Nuclear and Cytoplasmic Extraction Reagents (Pierce, Thermo Fisher Scientific) were used for cellular fractionation. Lysates were denatured by Laemmli sample buffer (Bio-Rad Laboratories Inc., Hercules, CA, USA) with 2-mercaptoethanol (Sigma-Aldrich). After SDS-PAGE, the separated polypeptides were transferred to Immobilon transfer membrane (Millipore, Merck KGaA). The first antibodies used in the present study were: affinity purified anti-SMG1 rabbit antiserum was obtained by immunization with synthesized peptide GCAVSVWKRVKAKLEGRDVD; goat anti-Upf 1 (P-14), goat anti-Upf2 (C-18), rabbit anti-ubiquitin and mouse anti-lamin A/C (636) were purchased from Santa Cruz Biotechnology Inc., (Santa Cruz, CA, USA) and rabbit anticaspase-3 was obtained from Cell Signaling Technology Inc. (Danvers, MA, USA). Mouse anti- $\beta$-actin was purchased from Sigma-Aldrich. Bound first antibodies were detected by adequate HRP-conjugated second antibody (Pierce) and SuperSignal West Femto maximum sensitivity substrate (Pierce) was used for detection. The resultant chemiluminescence was captured by cooled CCD camera system (Atto Corp., Tokyo, Japan) and quantified using Image processing software (Image J).

Immunofluorescence analysis. The immunostaining method had been described previously (13). For anti-luciferase and SMG1 siRNA transfection, we subjected exponentially growing A549 cells on Lab-Tek II chamber slide (Nalge Nunc, Thermo Fisher Scientific). After one day's culture, cells were washed wish PBS and fixed with cold methanol at $4{ }^{\circ} \mathrm{C}$ for $20 \mathrm{~min}$. Then, after being permeated with $0.1 \%$ Triton $\mathrm{X}-100$ and treated with $10 \%$ fetal calf serum, cells were incubated with $1 \%$ bovine serum albumin as negative control or one of the following first antibodies overnight at $4^{\circ} \mathrm{C}$ : anti-SMG1, antiUpf 1 and anti-Upf 2 antiserum. After washing to remove excess primary antibodies, cells were incubated for $0.5 \mathrm{~h}$ at RT with Alexa Fluor 594 chicken anti-rabbit or goat IgG (Invitrogen, Life Technologies, Carlsbad, CA, USA). Finally cells were observed and images taken by fluorescence microscopy.

Immunoprecipitation. Cell pellets were sonicated in NET-2 buffer (50 mMTris-HCl,300 mMNaCl,0.05\% IGEPAL-CA630) and centrifuged. Clarified supernatants were incubated with the primary antibodies against Upf1, ubiquitin or normal IgG (Santa Cruz Biotechnology Inc.), which were immobilized on protein A/G beads suspended in NET-2 buffer. Following 3-h incubation at $4^{\circ} \mathrm{C}$ with gentle rotation, beads were washed extensively five times with lysis buffer, boiled in Laemmli sample buffer and microcentrifuged. Purified polypeptides were separated in SDS-PAGE and detected with western blot analysis with specific antibodies against Upf1 or ubiquitin.

Statistical analysis. To evaluate the significance of average, we used Student's t-test. The level of statistical significance was set at $\mathrm{P}<0.05$.

\section{Results}

Proteasome inhibitors cause the accumulation of Upf1 and Upf 2 proteins. To reveal the relationship between UPS and NMD pathway, we examined the effects of ubiquitin-proteasome inhibitors, such as MG132 (MG) and lactacystin (LAC), on the stabilization and accumulation of Upf proteins. Both Upf1 and 2 are putative ubiquitin substrates that have been identified recently (12). Cycloheximide (CHX), a translation inhibitor, and wortmannin (WORT), a PI-3 kinase inhibitor, are often used as NMD inhibitors and they can cause the accumulation of nonsense-containing mRNAs. To identify the underlying mechanisms of Upf1 and Upf2 accumulation, we compared the effects of these inhibitors. As shown in Fig. 1, 6-h treatment with CHX or WORT caused accumulation of Upf1 and Upf2 proteins. However, 12-h treatment with CHX slightly reduced both of them, which might be caused by spontaneous degradation with blocked protein synthesis. On the other hand, MG or LAC treatment caused significant accumulation of Upf1 and Upf 2 proteins.

These results prompted us to speculate that Upf1 and Upf2 would be target molecules of ubiquitination. To investigate this possibility, we tried detection of higher band shift caused by polyubiquitination of Upf1 proteins. However, we detected no band shift of either unpurified Upf1 or immuno-precipitated Upf1, and no signal of ubiquitin conjugation was detected even in immuno-purified Upf1 (Fig. 2). The accumulation of Upf1 could not be accounted for by the fraction of a very small band shift in MG treated cells. In conclusion, our experiments provided no clear evidence for polyubiquitination of Upf1 and proposed that the target molecule(s) of ubiquitin-proteasome might downregulate the amount of Upf1 directly or indirectly.

Knockdown of SMG1 causes the accumulation of Upf1 and Upf 2 proteins. A549 cells were transfected with SMG1-1 (5032) siRNA against SMG1 mRNA and their lysates were analyzed by western blotting with specific antibodies. As shown in Fig. 3, SMG1 was downregulated by siRNA transfection successfully as compared to control cells transfected with anti-luciferase siRNA. As mentioned in a previous publication (7), short and long isoforms of SMG1 were detected by our antiserum and both were knocked down by siRNA in the present study. We found that both Upf1 and Upf2 proteins increased significantly in SMG1 knockdown cells. Next, we used another SMG1-2 siRNA (2999) molecule and transfected it to A549 cells. It caused similar accumulations of Upf 1 and $U$ pf 2 proteins. From these results, we 


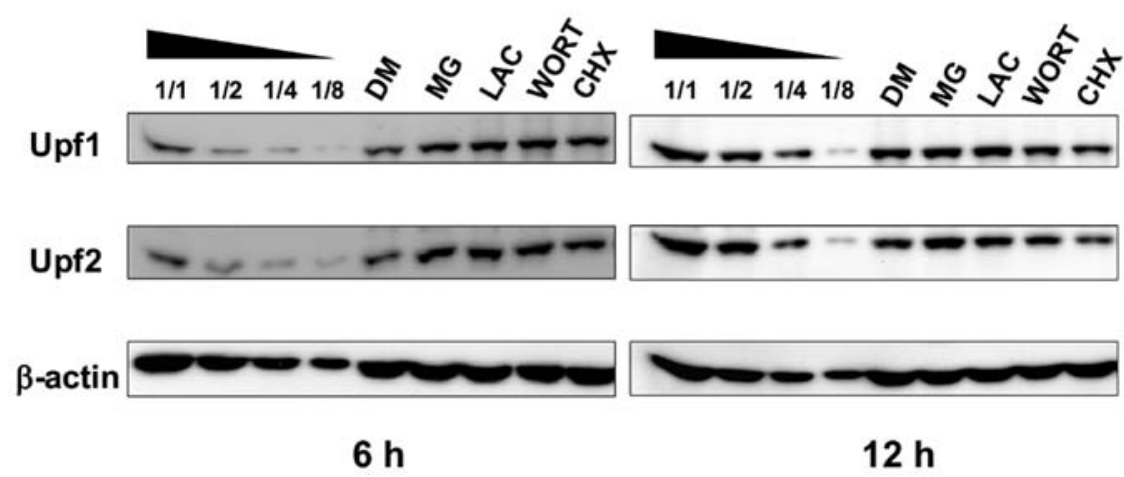

Figure 1. Proteasome inhibitors cause the accumulation of Upf1 and Upf2 proteins. Upf1 and Upf2 protein levels were detected by western blot analysis after 6- or 12-h treatment with DMSO (DM), MG132 (MG), lactacystin (LAC), wortmannin (WORT) and cycloheximide (CHX).
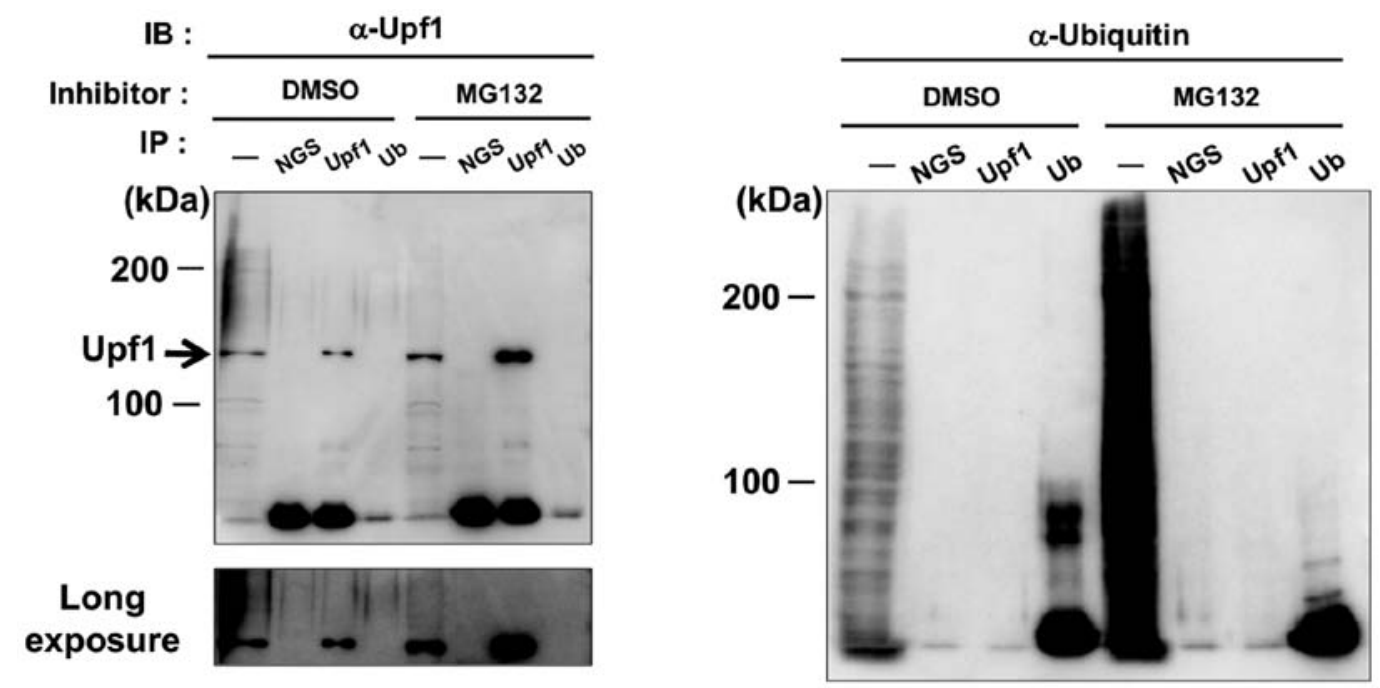

Figure 2. The accumulation of Upf1 could not be accounted for by the fraction of a very small band shift in MG132 treated A549 cells. To investigate whether Upf1 and Upf 2 were target molecules of ubiquitination, we tried detection of higher band shift in DMSO- and MG132-treated A549 cells with immunoprecipitation method. IB, immunoblotting; IP, immunoprecipataion; Ub, ubiquitin.
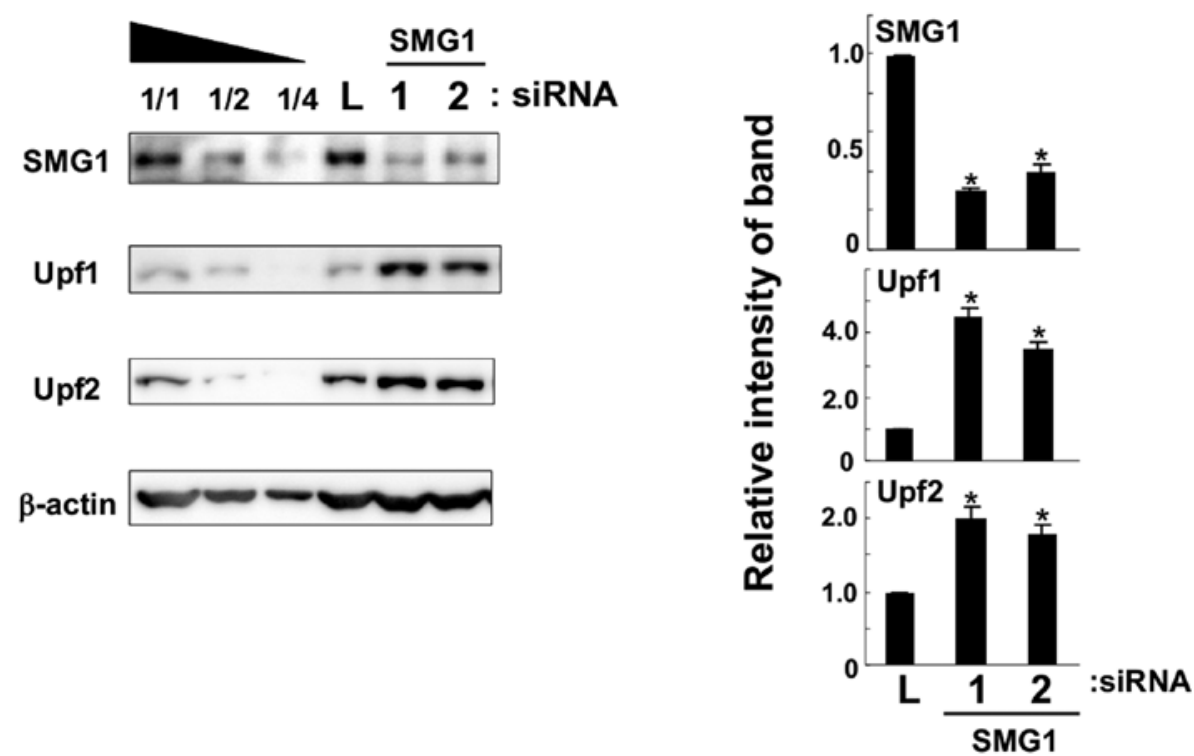

Figure 3. Knockdown of SMG1 causes the accumulation of Upf1 and Upf2 proteins. A549 cells were transfected with two different sequences (5032 and 2999$)$ of siRNA against SMG1 mRNA and their lysates were analyzed by western blot with specific antibodies. L, luciferase; 1, 5032 siRNA; 2, 2999 siRNA. Results are depicted as the mean \pm SEM. ${ }^{*} \mathrm{P}<0.01$ vs. luciferase group. 

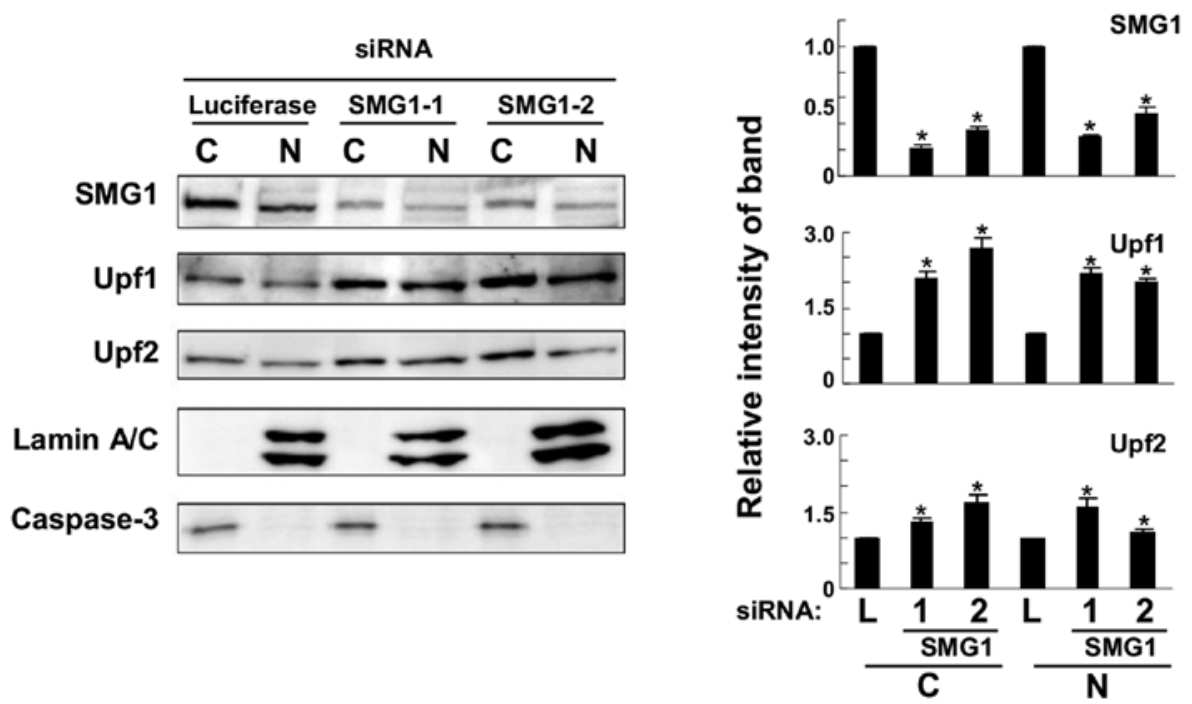

Figure 4. Knockdown of SMG1 causes the accumulation of Upf1 and Upf2 proteins in both nuclear and cytoplasmic fractions. To determine the cellular fraction where Upf1 and Upf2 accumulated, western blot analysis was performed with fractionated cellular lysates of A549 cells. The efficiency of fractionation was confirmed by an enrichment of nuclear specific marker Lamin A/C and cytoplasmic marker, caspase-3. C, cytoplasm; N, nucleus; SMG1-1, 5032 siRNA; SMG1-2, 2999 siRNA. Results are depicted as the mean \pm SEM. "P $<0.01$ vs. luciferase group.
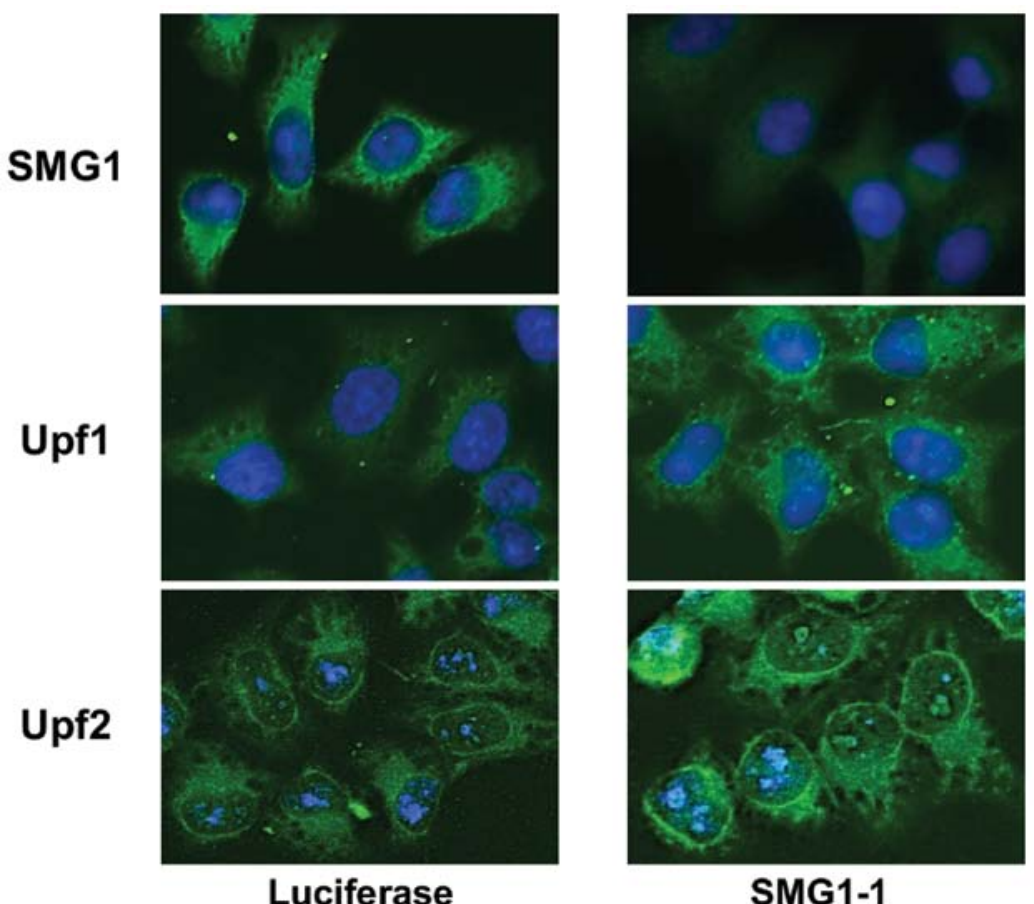

SMG1-1

\section{: siRNA}

Figure 5. Knockdown of SMG1 causes augmentation of the fluorescence signals in Upf1 and Upf2 proteins. Immunofluorescence staining was performed to detect the location of Upf1 and Upf2 proteins in A549 cells after luciferase or SMG1 siRNA knockdown. SMG1-1, 5032 siRNA.

concluded that SMG1 knockdown could cause the accumulation of Upf1 and Upf2 proteins in cultured cells.

To determine the cellular fraction where Upf1 and Upf2 accumulated, western blot analysis was performed with fractionated cellular lysates. As shown in Fig. 4, the efficiency of fractionation was confirmed by an enrichment of nuclear specific marker lamin A/C and cytoplasmic marker, caspase-3. Specific bands were observed in fractions. They were knocked down successfully in both fractions by SMG1 siRNA transfection. In this condition, Upf 1 and Upf 2 proteins increased in both nuclear and cytoplasmic fractions. It seemed that SMG1 could downregulate the amounts of Upf1 and Upf2 proteins in nuclear and cytoplasmic fraction.

To get morphologic evidence, we performed immunofluorescence staining to test the location of Upf1 and Upf2 proteins. By using specific antibodies, we observed that Upf1 was evenly distributed throughout the cytoplasm, while Upf2 showed strong perinuclear staining (Fig. 5). With anti-SMG1 siRNA knockdown, the fluorescence signals of SMG1 in cells weakened significantly, which suggested successful knock- 


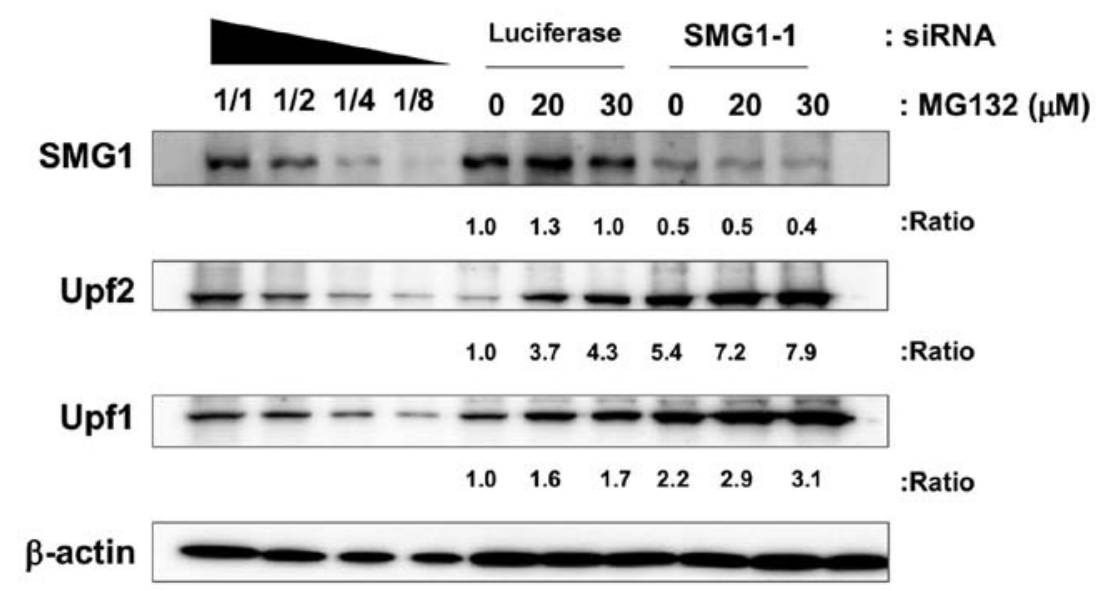

Figure 6. Additive effects of proteasome inhibitors and SMG1 knockdown on augmentation of Upf1 and Upf2 proteins. Luciferase- and SMG1-knocked down cells were treated with 0, 20, $30 \mu \mathrm{M}$ MG132 for $12 \mathrm{~h}$. Upf1 and Upf2 protein levels were examined by western blot analysis. For the knockdown, SMG1-1 (5032 siRNA) was used.

down of SMG1. Moreover, we found the fluorescence signals of Upf1 and Upf 2 increased respectively, which confirmed our results described in Fig. 3.

Additive effects of SMG1 knockdown and proteasome inhibitors. To test whether SMG1 knockdown and ubiquitinproteasome inhibitors share the same pathway to cause the accumulation of Upf1 and Upf2, we treated SMG1-knocked down cells with proteasome inhibitors and the lysates for immunoblot were obtained. If they affected increments of Upf1 and Upf2 independently, an additional accumulation should be expected. As shown in Fig. 6, SMG1 knockdown and proteasome inhibitor MG caused accumulation of Upf1 and Upf2, respectively. Moreover, in SMG1 knocked down cells, we detected additive effects of Upf1 and Upf2 accumulation with proteasome inhibitor treatment. In the real-time PCR results, we could not observe any significant upregulation of mRNA levels of Upf1 and Upf2 in proteasome inhibitor treated cells (data not shown). From these results, we propose the possibility that SMG1 and ubiquitin-proteasome system acted on different mechanisms that regulated the amounts of Upf1 and Upf2 proteins.

\section{Discussion}

UPS is widely accepted as an attractive target for drug development due to the tremendous potential for intervention on multiple pathologies including cancer, neurodegenerative diseases, immune diseases and multiple infections (14). The most common form of the proteasome is known as $26 \mathrm{~S}$ proteasome. Inhibition of the proteolytic function of the $26 \mathrm{~S}$ proteasome in malignant cells provokes apoptosis, ER stress, cell cycle arrest and represses angiogenesis as well as metastasis (15).

There is a wide variety of natural and synthetic proteasome inhibitors that can be clustered into five groups: peptide aldehydes, peptide vinyl sulfones, peptide boronates, peptide epoxyketones and $\beta$-lactones (lactacystin and its derivatives). MG is the best known molecule of peptide aldehyde (16).
Bortezomib (Velcade ${ }^{\circledR}$ ), the first FDA approved proteasome inhibitor, belongs to the peptide boronate group. Bortezomib is now used as a treatment for multiple myeloma (MM), mantle cell lymphoma (MCL), non-small lung cancer and pancreatic cancer (17-19). Recently, carfilzomib has become the second generation product of this class of compounds. Several mechanisms have been revealed, such as downregulation of $\mathrm{NF \kappa B}$ and other anti-apoptotic proteins, activation of the tumor suppressor protein p53 and modulation of cell cycle proteins and other pro-apoptotic factors (20-25). However, the cellular mechanisms for their clinical efficacy have not been completely elucidated.

The biological and medical importance of NMD is highlighted by its ability to suppress potential dominantnegative effects of C-terminally truncated polypeptides (26). During the whole NMD pathway, different kinds of proteins and enzymes are required, which coordinate to induce the specific degradation of nonsense codon containing aberrant transcripts. It was reported that Upf1 potentially acts as an E3 ubiquitin ligase by its association with Upf3 in yeast (27). Kuroha et al also reported that Upf1 was required for rapid proteasome-mediated degradation of an aberrant protein (PTC product) derived from a PTC-containing mRNA (28). These reports revealed a possible correlation between NMD pathway and UPS. However, it is still unclear whether there is a regulative relationship between them.

In the present study, MG or LAC treatment caused the accumulation of Upf1 and Upf2 proteins, indicating that UPS might participate in the downregulation of the amount of Upf 1 and Upf2. However, our experiments provided no clear evidence for polyubiquitination of Upf1 and proposed the target molecule(s) of UPS might downregulate the amount of Upf1 directly or indirectly. Furthermore, our results showed the accumulation of Upf 1 and Upf 2 proteins in SMG1-knocked down cells. One reasonable interpretation of the upregulation of Upf1 and Upf2 is the accumulation of NMD intermediates. Because SMG1 is essential for decapping the nonsense containing mRNA, Upf1 and Upf 2 form an incomplete complex on mRNA in SMG1-knocked down cells. 
If this were true, Upf1 and Upf2 would be downregulated or broken down after carrying out NMD. In our studies, treatment with10 $\mu \mathrm{M}$ WORT, a PI-3 kinase inhibitor, did not cause the accumulation of Upf1 and Upf2, which suggested that their complex formation with SMG1 was required for NMD rather than phosphorylation of Upf1. Additionally, treatment with MG and SMG1 siRNA simultaneously caused an additive effect on Upf1 and Upf 2 amounts, which suggested the possibility that UPS and SMG1 regulate the amounts of Upf1 and Upf2 in different manner.

Recent studies have revealed the in vivo role of NMD factors. NMD reaction takes place on exon junction complex on mRNA and it consists of various factors (29). Magoh, one of the complex members, is the binding partner of RBM8A and the mutation of this gene resulted in the microcephaly in mice $(30,31)$. RBM8A is related to TAR (thrombocytopeniaabsent radii) syndrome in human and anxiety behavior in mice $(32,33)$. The exon junction complex seems to be required for normal development of mammals. On the other hand, Upf2 is required for various developmental stages such as cell proliferation, liver regeneration and synapse regulation (34-36). The copy number variation of Upf2 was related to neuro-developmental disorders in humans (37). The deficiency of Upf3b protein, a binding partner of Upf 2 , also causes various mental illnesses in human (38-41). Interestingly, the substantial part of transcriptome in Upf 2 deficient patients overlapped with the data sets from Upf3b deficient patients (37). Therefore, NMD factors seem to be required for the normal regulation of brain development and mental health. Thus, it may be possible that the proteasome inhibitor treatment could be used as care for neuro-development or mental disorders via the upregulation of Upf2 proteins.

In conclusion, our results partly revealed the quantitative regulation of Upf 1 and Upf 2 proteins by UPS and SMG1. It may help us understand the mechanisms underlining the anticancer effect of UPS inhibitors. The diverse involvement of NMD factors make the relationship between them complex, and further experiments are required.

\section{Acknowledgements}

This study was supported by grants from Kanazawa Medical University and Ministry of Education, Culture, Sports, Science and Technology, Japan (S2013-2, H2012-16 [S1201022]).

\section{References}

1. Groll M and Potts BC: Proteasome structure, function, and lessons learned from beta-lactone inhibitors. Curr Top Med Chem 11: 2850-2878, 2011.

2. Voges D, Zwickl P and Baumeister W: The 26S proteasome: a molecular machine designed for controlled proteolysis. Annu Rev Biochem 68: 1015-1068, 1999.

3. Maquat LE and Carmichael GG: Quality control of mRNA function. Cell 104: 173-176, 2011.

4. Neu-Yilik G and Kulozik AE: NMD: multitasking between mRNA surveillance and modulation of gene expression. Adv Genet 62: 185-243, 2008.

5. Maquat LE: Nonsense-mediated mRNA decay: splicing, translation and mRNP dynamics. Nat RevMol Cell Biol 5: 89-99, 2004.

6. Czaplinski K, Ruiz-Echevaria MJ, Gonzalez CI and Peltz SW: Should we kill the messenger? The role of the surveillance complex in translation termination and mRNA turnover. Bioessays 21: 685-696, 1999.
7. Yamashita A, Ohnishi T, Kashima I, et al: Human SMG-1, a novel phosphatidylinositol 3-kinase-related protein kinase, associates with components of the mRNA surveillance complex and is involved in the regulation of nonsense-mediated mRNA decay. Genes Dev 15: 2215-2228, 2001.

8. Kashima I, Yamashita A, Izumi N, et al: Binding of a novel SMG-1-Upf1-eRF1-eRF3 complex (SURF) to the exon junction complex triggers Upf1 phosphorylation and nonsense-mediated mRNA decay. Genes Dev 20: 355-367, 2006.

9. Silva AL and Romao L: The mammalian nonsense-mediated mRNA decay pathway: to decay or not to decay! Which players make the decision? FEBS Lett 583: 499-505, 2009.

10. Lykke-Andersen J, Shu MD and Steitz JA: Human Upf proteins target an mRNA for nonsense-mediated decay when bound downstream of a termination codon. Cell 103: 1121$1131,2000$.

11. Chamieh H, Ballut L and Bonneau F: NMD factors UPF2 and UPF3 bridge UPF1 to the exon junction complex and stimulate its RNA helicase activity. Nat Stuct Mol Biol 15: 85-93, 2008.

12. Danielsen JM, Sylvestersen KB, Bekker-Jensen S, et al: Mass spectrometric analysis of lysine ubiquitylation reveals promiscuity at site level. Mol Cell Proteomics 10: M110.003590, 2011.

13. Ishigaki Y, Nakamura Y, Takehara T, et al: Scanning electron microscopy with an ionic liquid reveals the loss of mitotic protrusions of cells during the epithelial-mesenchymal transition. Microsc Res Tech 74: 1024-1031, 2011.

14. Xolalpa W, Perez-Galan P, Rodríguez MS, et al: Targeting the ubiquitin proteasome system: beyond proteasome inhibition. Curr Pharm Des 19: 4053-4093, 2013.

15. Buac D, Shen M, Schmitt S, et al: From Bortezomib to other inhibitors of the proteasome and beyond. Curr Pharm Des 19: 4025-4038, 2013.

16. Kisselev AF and Goldberg AL: Proteasome inhibitors: from research tools to drug candidates. Chem Biol 8: 739-758, 2001.

17. Aghajanian C, Soignet S, Dizon DS, et al: A phase I trial of the novel proteasome inhibitor PS341 in advanced solid tumor malignancies. Clin Cancer Res 8: 2505-2511, 2002.

18. Richardson PG, Barlogie B, Berenson J, et al: A phase 2 study of bortezomib in relapsed, refractory myeloma. N Engl J Med 348: 2609-2617, 2003.

19. Scagliotti G: Proteasome inhibitors in lung cancer: Crit Rev Oncol Hematol 58: 177-189, 2006.

20. Crawford LJ, Walker B and Irvine AE: Proteasome inhibitors in cancer therapy. J Cell Commun Signal 5: 101-110, 2011.

21. Lopes UG, Erhardt P, Yao R, et al: P53-dependent induction of apoptosis by proteasome inhibitors. J Biol Chem 272: 12893-12896, 1997.

22. Pleban E, Bury M, Mlynarczuk I, et al: Effects of proteasome inhibitor PSI on neoplastic and non-transformed cell lines. Folia Histochem Cytobiol 39: 133-134, 2001.

23. Nakanishi $\mathrm{C}$ and Toi M: Nuclear factor-kappa B inhibitors as sensitizers to anticancer drugs. Nat Rev Cancer 5: 297-309, 2005.

24. Mitsiades N, Mitsiades CS, Poulaki V, et al: Molecular sequelae of proteasome inhibition in human multiple myeloma cell. Proc Natl Acad Sci USA 99: 14374-14379, 2002.

25. Russo A, Bronte G, Fulfaro F, et al: Bortezomib: a new pro-apoptotic agent in cancer treatment. Curr Cancer Drug Targets 10: 55-67, 2010.

26. Garneau NL, Wilusz $\mathbf{J}$ and Wilusz CJ: The highways and byways of mRNA decay. Nat Rev Mol Cell Biol 8: 113-126, 2007.

27. Takahashi S, Araki Y, Ohya Y, et al: Upf1 potentially serves as a RING-related E3 ubiquitin ligase via its association with Upf3 in yeast. RNA 14: 1950-1958, 2008.

28. Kuroha K, Tatematsu T and Inada T: Upf1 stimulates degradation of the product derived from aberrant messenger RNA containing a specific nonsense mutation by the proteasome. EMBO Rep 10: 1265-1271, 2009.

29. Melero R, Buchwald G, Castaño R, et al: The cryo-EM structure of the UPF-EJC complex shows UPF1 poised toward the RNA 3' end. Nat Struct Mol Biol 19: 498-505, 2012.

30. Silver DL, Watkins-Chow DE, Schreck KC, et al: The exon junction complex component Magoh controls brain size by regulating neural stem cell division. Nat Neurosci 13: 551-558, 2010.

31. Silver DL, Leeds KE, Hwang HW, et al: The EJC component Magoh regulates proliferation and expansion of neural crestderived melanocytes. Dev Biol 375: 172-181, 2013. 
32. Albers CA, Paul DS, Schulze H, et al: Compound inheritance of a low-frequency regulatory SNP and a rare null mutation in exon-junction complex subunit RBM8A causes TAR syndrome. Nat Genet 44: 435-439, 2012.

33. Alachkar A, Jiang D, Harrison M, et al: An EJC factor RBM8a regulates anxiety behaviors. Curr Mol Med 13: 887-899, 2013.

34. Weischenfeldt J, Damgaard I, Bryder D, et al: NMD is essential for hematopoietic stem and progenitor cells and for eliminating by-products of programmed DNA rearrangements. Genes Dev 22: 1381-1396, 2008.

35. Long AA, Mahapatra CT, Woodruff EA III, et al: The nonsense-mediated decay pathway maintains synapse architecture and synaptic vesicle cycle efficacy. J Cell Sci 123: 3303-3315, 2010.

36. Thoren LA, Nørgaard GA, Weischenfeldt J, et al: UPF2 is a critical regulator of liver development, function and regeneration. PLoS One 5: e11650, 2010.

37. Nguyen LS, Kim HG, Rosenfeld JA, et al: Contribution of copy number variants involving nonsense-mediated mRNA decay pathway genes to neuro-developmental disorders. Hum Mol Genet 22: 1816-1825, 2013.
38. Jolly LA, Homan C, Jacob R, et al: The UPF3B Gene, implicated in intellectual disability, autism, ADHD and childhood onset Schizophrenia regulates neural progenitor cell behaviour and neuronal outgrowth. Hum Mol Genet: July 10, 2013 (Epub ahead of print).

39. Nguyen LS, Jolly L, Shoubridge C, et al: Transcriptome profiling of UPF3B/NMD-deficient lymphoblastoid cells from patients with various forms of intellectual disability. Mol Psychiatry 17: 1103-1115, 2012.

40. Szyszka P, Sharp SI, Dedman A, et al: A nonconservative amino acid change in the UPF3B gene in a patient with schizophrenia. Psychiatr Genet 22: 150-151, 2012.

41. Addington AM, Gauthier J, Piton A, et al: A novel frameshift mutation in UPF3B identified in brothers affected with childhood onset schizophrenia and autism spectrum disorders. Mol Psychiatry 16: 238-239, 2011. 